tially indexed time series, in the case of empirical orthogonal function analysis). The results of singular spectrum analysis consist of a number of orthogonal index series, each a linear smoothing of the original time series, with variance decreasing from the maximum possible. Actually, the index series are technically not linear smoothings of the original time series. The reason is that the weights used to construct them depend on an estimate of the autocovariance function of the original time series, and this estimate is itself a nonlinear function of the original time series.

As in principal component analysis, once the index series have been constructed, they can be interpreted (e.g., as secular trend, a periodic oscillation, etc.) and the original time series can be projected onto a subset of them. An important problem concerns the assessment of the significance of one or more of the index series. Elsner and Tsonis discuss this problem in some detail. They point out that, in assessing significance, it is important to specify the null model. Too often in this kind of work the null model is white noise, which is unrealistic for many, if not most, geophysical time series.

The final part of the book describes the application of singular spectrum analysis to signal detection, filtering, prediction, and, although it is somewhat out of place, phase space reconstruction. The authors cover a lot of ground here and it is clear that some sorting out of methods needs to be done.

I am not enthusiastic about singular spectrum analysis. My main reservation is that I do not believe that it is possible to get much out of a time series without making some assumptions about its structure. I have a specific worry that the orthogonality constraint applied in singular spectrum analysis can lead to artifacts to which physical interpretations are attached. I also worry that statistical issues, such as the assessment of the significance of a component, have not been thought out carefully. That said, I am enthusiastic about this book. It provides a clear, concise description of a method that has gained some currency in atmospheric science. Whether this method stands or falls, it is important that it be understood. This book certainly contributes to that understanding.-Andrew R. Solow.

Andrew $R$. Solow is a researcher at Woods Hole Oceanographic Institution, Woods Hole, Massachusetts.

\section{Publishers' Addresses}

Addison-Wesley

Jacob Way, Rt. 128

Reading, MA 01867

Telephone: 800-447-2226

Computational Mechanics, Inc. 25 Bridge St.

Billerica, MA 01821

Telephone: 508-667-5841

Oxford University Press

198 Madison Ave.

New York, NY 10016-4314

Telephone: 800-451-7556

Plenum Publishing

233 Spring St.

New York, NY 10013

Telephone: 800-22 1-9369

University Science Books

20 Edgehill Rd.

Mill Valley, CA 94941

415-383-1430

\section{Water Resources Publications \\ 7200 East Dry Creek Rd. Suite E-104 \\ Englewood, CO 80112 \\ Telephone: 800-736-2405}

\section{EDITOR'S NOTE}

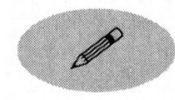

The Bulletin relies on its readership for timely information on members' accomplishments, chapter happenings, conferences, and science fairs.

- About Our Members

- Chapter News

- Announcements

- Science Fairs

Submit contributions to Bulletin News Editor, AMS, 45 Beacon St., Boston, MA 02108-3693; fax 617742-8718; e-mail: jburba@ametsoc.org. 